Société d'histoire de la révolution de 1848 et des

révolutions du XIXe siècle

48 | 2014

Usages du droit

\title{
Wolf LEPENIES, Auguste Comte. Le pouvoir du signe
}

Bibliothèque allemande, Paris, Éditions de la Maison des sciences de l'homme, 2012 ( $1^{\text {re }}$ édition en allemand, 2010), 131 p. ISBN :

978-2-7351-1515-0. 24 euros.

\section{Nathalie Richard}

\section{OpenEdition \\ Journals}

Édition électronique

URL : http://journals.openedition.org/rh19/4694

DOl : $10.4000 /$ rh 19.4694

ISSN : $1777-5329$

Éditeur

La Société de 1848

Édition imprimée

Date de publication : 1 juin 2014

Pagination : 197-198

ISSN : 1265-1354

Référence électronique

Nathalie Richard, "Wolf LEPENIES, Auguste Comte. Le pouvoir du signe », Revue d'histoire du XIXe siècle [En ligne], 48 | 2014, mis en ligne le 18 septembre 2014, consulté le 22 septembre 2020. URL : http:// journals.openedition.org/rh19/4694; DOI : https://doi.org/10.4000/rh19.4694

Ce document a été généré automatiquement le 22 septembre 2020.

Tous droits réservés 


\title{
Wolf LEPENIES, Auguste Comte. Le pouvoir du signe
}

\author{
Bibliothèque allemande, Paris, Éditions de la Maison des sciences de \\ l'homme, 2012 ( $1^{\text {re }}$ édition en allemand, 2010), 131 p. ISBN :
}

978-2-7351-1515-0. 24 euros.

\section{Nathalie Richard}

\section{RÉFÉRENCE}

Wolf LEPENIES, Auguste Comte. Le pouvoir du signe, Bibliothèque allemande, Paris, Éditions de la Maison des sciences de l'homme, 2012 (1 ${ }^{\text {re }}$ édition en allemand, 2010), 131 p. ISBN : 978-2-7351-1515-0. 24 euros.

1 Des réflexions de Comte et de la politique positiviste des images subsistent quelques traces connues : sa statue sur la place de la Sorbonne ; la couleur, le dessin et la devise du drapeau brésilien. Ce sont ces réflexions théoriques et cette politique concertée qu'entreprend de restituer Wolf Lepenies dans Auguste Comte. Le pouvoir des signes.

2 Après la mort de sa maîtresse, Clotilde de Vaux, et à la faveur de la révolution de 1848, Comte prend conscience de la "sécheresse morale » de la philosophie exposée dans le Cours de philosophie positive (1830-1842). Il engage des réflexions sur une politique et une religion qui viendraient la compléter et assurer son effectivité. S'esquisse alors ce que Wolf Lepenies désigne comme l'«iconic turn» (p. 3) du positivisme, commandant une nouvelle politique des images, principalement inspirée du catholicisme.

3 Autour de la question du portrait du fondateur et de sa diffusion, l'ouvrage restitue les liens entre des artistes (Félix Bracquemond, Antoine Étex) et le mouvement positiviste. Antoine Étex notamment, sculpteur de certains reliefs de l'Arc de triomphe de l'Étoile, fut considéré par Comte comme un véritable artiste positiviste. Il réalisa un buste et un portrait approuvés par leur modèle et reproduits en séries. Diffusés parmi les disciples, comparables aux images du Christ ou de la Vierge, ils sont pensés principalement comme des instruments de consolidation sociale et spirituelle du mouvement. 
Sensible aux transformations de l'espace public, Comte pense également l'image comme instrument de diffusion de masse et fonde une Société de propagande positiviste chargée d'élaborer des affiches. Parisien d'adoption, promeneur aux habitudes rangées, Comte est un penseur du centralisme. Sa position d'examinateur externe à l'École polytechnique le contraint à de longs périples, où se confirme à ses yeux la suprématie de la capitale sur la province. Comte pense Paris (nouvelle Rome ou nouvelle Athènes, suivant que le modèle est le catholicisme ou la philosophie) comme premier centre universel du positivisme, ville sainte destinée à être supplantée par Constantinople une fois seulement que la doctrine aura triomphé à la surface de la Terre. La capitale est en effet, à ses yeux, le lieu où peut s'opérer l'alliance des philosophes et des prolétaires, indispensable à la victoire puis au fonctionnement de l'État positif ; elle est aussi le centre d'un espace national destiné à être réorganisé en seize régions positivistes.

Dans cette ville-centre, doit se développer une politique des monuments pour laquelle Comte a élaboré un plan d'ensemble, sur le modèle révolutionnaire. Après sa mort, c'est surtout à l'inscription du souvenir du fondateur dans l'espace urbain que travaillent les disciples. Outre l'entretien de la tombe du Père-Lachaise, objet d'un pèlerinage annuel, ils œuvrent à la désignation d'une rue, obtenue en 1885 , et à l'érection d'une statue, inaugurée en 1902 sur la place de la Sorbonne.

6 S'appuyant principalement sur la correspondance publiée du philosophe, l'ouvrage restitue ainsi la place qu'occupent, dans la pensée comtienne, la question des symboles et de la propagande, de même que la réflexion sur les lieux jugés les plus propices à l'élaboration et à la diffusion de la doctrine. Le fondateur du positivisme y est dépeint comme un penseur lucide de la modernité (de la ville, du pouvoir des images, de la propagande politique), capable de s'inspirer de modèles hétéroclites, anciens ou plus récents, religieux ou laïques. On pourra regretter peut-être, qu'exclusivement centré sur les positivistes, l'ouvrage ne permette pas d'évaluer pleinement l'originalité ou la banalité de la pensée de Comte, face à d'autres promoteurs de politiques des images du $\mathrm{XIX}^{\mathrm{e}}$ siècle ou face à des penseurs mieux connus et mieux étudiés de ces questions (Walter Benjamin par exemple). 